\title{
Activity Pattern of Brocket Deer (Genus Mazama) in the Atlantic Forest: Does Sampling Design Affect the Patterns?
}

\author{
Ana Carolina Srbek-Araujo $0^{1,2,3,4 *}$, Tayná Seabra ${ }^{1}$ and Giovanna Colnago Cecanecchia ${ }^{1,2}$ \\ ${ }^{1}$ Laboratório de Ecologia e Conservação de Biodiversidade (LECBio), Universidade Vila Velha - UVV, Rua Comissário José Dantas de Melo, no 21 , Bairro \\ Boa Vista, Vila Velha, Espírito Santo, Brazil
}

${ }^{2}$ Programa de Pós-graduação em Ecologia de Ecossistemas, Universidade Vila Velha - UVV, Brazil

${ }^{3}$ Programa de Pós-graduação em Ciência Animal, Universidade Vila Velha - UVV, Brazil

${ }^{4}$ Instituto SerraDiCal de Pesquisa e Conservação, Belo Horizonte, Minas Gerais, Brazil

Submission: June 25, 2019; Published: September 19, 2019

*Corresponding author: Ana Carolina Srbek-Araujo, Laboratório de Ecologia e Conservação de Biodiversidade, Programa de Pós-graduação em Ecologia de Ecossistemas, Programa de Pós-graduação em Ciência Animal, Universidade Vila Velha, Vila Velha, Espírito Santo, Brazil

\section{Abstract}

This study aimed to describe the activity pattern of Mazama spp. in an Atlantic Forest remnant in southeastern Brazil, and to test whether the sampling design can affect the recorded patterns. Data from 4 sampling periods were analyzed (June 2005 to February 2010 ), using different sampling designs, and these included camera trapping installed along internal unpaved roads or in the forest interior. The records of Mazama spp. were collected throughout the day, with no periods of inactivity, similarly to the results from other regions in South America, but differently from a previous study developed in the same sampled area. There was variation in the distribution of records throughout the day when the sampling periods/designs were compared, but the activity patterns were not statistically different when compared the 2 types of habitat sampled (internal roads and forest interior). Sampling design affect the activity pattern recorded for Mazama spp., which may be related to behavioral differences in response to spatial variations in habitat on a local/regional scale. We recommended the combined use of different sampling designs to better describe the activity pattern of species in camera trap studies, reinforcing that the risk of sample bias should be weighed during the study design.

Keywords: Artiodactyla, Camera trap, Cervidae, Circadian rhythm, Detectability, Mazama americana, Mazama gouazoubira.

\section{Introduction}

The time of day in which a species is active is an expression of its circadian rhythm. This consists of approximately 24 -h intervals associated with the light-dark cycle and is responsible for the regulation of biological processes [1]. Biological rhythmicity is extremely important because it promotes an internal temporal organization in the physiology and behavior of living beings, and it enables them to synchronize with the external environment to anticipate and prepare for periodic environmental changes [2,3].

The methods used in studies on activity pattern include camera traps. However, despite the increasing use of this equipment in natural history studies of various taxa [46], differences related to sampling design, combined with differences in habitat use and species behavior, can affect the records obtained by this sampling method [7].
Brocket deer in the genus Mazama (Rafinesque, 1817) have a complex evolutionary pattern, and the genus is represented by morphologically similar Neotropical species grouped in 2 main clades: the red brocket group and the gray brocket group [8]. These deer occur from southern Mexico to northern Argentina, including practically the entire Brazilian territory [9]. They are morphologically adapted to forest habitats, although they are also found in different vegetation types throughout their distribution, as such as Cerrado (the Brazilian Savanna), Caatinga (xeric shrubland and thorn forest) and open field formations, as well as capoeiras (secondary-growth forests in initial stages of regeneration) [9]. There are 4 species of Mazama recognized for the Brazilian Atlantic Forest [10]. Mazama americana (Erxleben, 1777) and Mazama gouazoubira (G. Fischer, 1814), which represent respectively the red and gray groups [8], are sympatric 
in the southeast of the country.

Studies on activity pattern of $M$. americana and $M$. gouazoubira are still scarce (if considering the wide geographic distribution of these species), and in some cases, the available data are conflicting [4,11-16]. It is thus necessary to investigate the discrepancies between studies to better define the activity patterns of these taxa, and to determine the environmental factors that may influence the time of day in which Mazama spp. are active, as well as check the sampling factors that may affect the collection of records used in studies on activity patterns.

The objective of the present study was to describe the activity pattern of Mazama spp. in an Atlantic Forest remnant in southeastern Brazil, and to test whether the camera trap sampling design can affect the recorded patterns.

\section{Materials and Methods}

\section{Study Area}

The study was conducted at Reserva Natural Vale (RNV, Vale Natural Reserve: $19^{\circ} 06^{\prime}-19^{\circ} 18^{\prime} \mathrm{S}$ and $39^{\circ} 45^{\prime}-40^{\circ} 19^{\prime} \mathrm{W}$ ), which is located between the municipalities of Linhares and Jaguaré, in the north of the state of Espírito Santo, southeastern Brazil (Figure 1). The RNV has an area of 22,711 ha and is adjacent to the Reserva Biológica de Sooretama (RBS, Sooretama Biological
Reserve - 27,860 ha). Together with other 2 private reserves (Recanto das Antas Private Natural Heritage Reserve - 2,212 ha, and Mutum Preto Private Natural Heritage Reserve - 379 ha), the RNV and RBS form a practically continuous block of native vegetation (Linhares-Sooretama Block - more than 53,000 ha) that represents approximately $11 \%$ of the current forested area in the state of Espírito Santo (based on data available in [17]). The Linhares-Sooretama Block is intersected by BR-101 Highway in the southwest/northeast direction.

The RNV is composed by a mosaic of habitats, most of which are covered by dense lowland forest (Tabuleiro forest) as well as areas with less dense forest on sandy soils (Mussununga) and occasional native grassland [18]. The forest vegetation in the RNV is classified as perennial seasonal forest [18]. The topography of the RNV is practically flat with tabular hills that vary in altitude between 28 and $65 \mathrm{~m}$ [18]. The climate in the region is tropical with dry winters, i.e., type Aw according to the Köppen classification system [19]. The mean annual temperature is $24 \cdot 3^{\circ} \mathrm{C}$, and the mean annual rainfall is $1,215 \pm 260 \mathrm{~mm}$ [20]. The RNV has an internal network of unpaved roads (Figure 1), which are approximately $4 \mathrm{~m}$ wide and total $126 \mathrm{~km}$ in length, allowing access to all parts of the reserve [18].
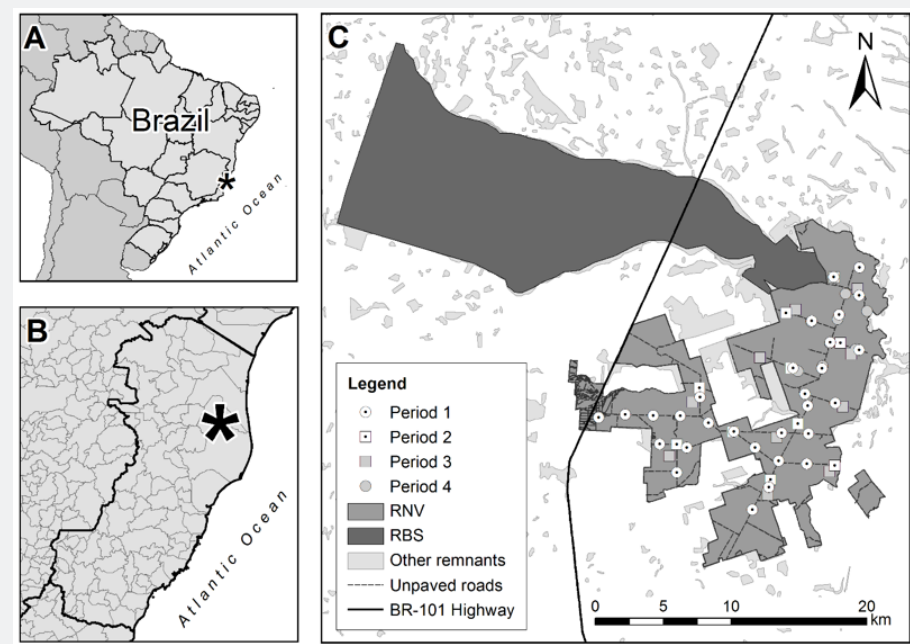

Figure 1: Location of the Reserva Natural Vale (RNV) in northern of the state of Espírito Santo, southeastern Brazil (A and B), including the limits of the RNV and the Reserva Biológica de Sooretama (RBS), comprising the Linhares-Sooretama Block (C). The sampling stations in each sampling period are also shown, as well as the internal unpaved roads, the BR-101 Highway and other Atlantic Forest remnants.

\section{Data Collection}

Data were collected during approximately 48 months of sampling, which were distributed in 4 distinct sampling periods using camera traps: Jun/2005 to Jun/2006 (Period 1), Jun/2006 to Aug/2007 (Period 2), Aug/2007 to Oct/2008 (Period 3), and Jun/2009 to Feb/2010 (Period 4). CamTrakker game cameras (CamTrak South Inc., USA) were used in the first sampling period; and Tigrinus cameras (conventional model; Tigrinus
Equipamentos para Pesquisa, Brazil) were used in the other 3 periods.

Each sampling period represented a distinct sample design, as described below. In the first and fourth periods, the camera traps were installed along internal unpaved roads; and in the second and third periods, the equipment were installed out of roads, in the interior of the forest (at 100-200 m, and $500 \mathrm{~m}$ from the nearest internal road, respectively; Figure 1). In the first 
period, 30 sampling stations were selected that were distributed in the north, south, and west subareas of the reserve (10 stations in each subarea), and data were collected in the dry and rainy seasons (2 consecutive months in each season/subarea). In Period 2, 10 different sampling stations distributed throughout the entire RNV were sampled. The same was done for Period 3. In Period 4, 8 sampling stations were selected in the north subarea.

The camera traps were operated for 24 hours/day, and the equipment was set to stamp the date and the time of the record at each photograph. The solar time was used for the time of day throughout the entire sampling period. The interval between consecutive photos was set to 20 seconds. The camera traps were fixed on tree trunks approximately $45 \mathrm{~cm}$ above the ground, and checked every 30 days for cleaning, battery replacement and to collect the photographic records. No bait was used to attract specimens.

\section{Assuming Limitations on the Identification of Mazama Species}

At first, we selected good quality photographic records of Mazama spp. to confirm the identification of the species present in the RNV. The photographs were sent to the Cervidae Research and Conservation Center (Núcleo de Pesquisa e Conservação de Cervídeos - NUPECE, from Universidade Estadual Paulista UNESP) for identification by cervid specialists (José Maurício Barbanti Duarte and Márcio Leite de Oliveira). A total of 56 photographic records were selected. Of these, 6 were identified as M. americana; 4 as M. gouazoubira; 39 were identified as from gray clade, but apparently different from M. gouazoubira; 3 were identified as from red clade, but apparently different from M. americana; 2 were classified as potential hybrids; and 2 did not receive any identification (Clade or species level;Appendix 1). According to Duarte et al. [8], the morphological similarity between the taxa has caused numerous errors in the identification of Mazama spp., and external morphometry by itself has low power in species discrimination. Thus, given the difficulty in identifying the species from most of the photographic records, even by specialist researchers, and the existence of many doubtful records, we chose to keep the data analysis at the genus level.

\section{Data Analysis}

To avoid double counting of records in the same capture event, only the first record of Mazama spp. was considered valid when there was more than one photo of the genus within a period of 1 hour at each sampling station (= independent record; [7]). To compare the number of independent records obtained in each sampling period/design according to differences in the effective sampling effort, the capture success of Mazama spp. in each sampling period was calculated by dividing the number of valid records by the sampling effort and multiplying the result by $100[7,21]$. The sampling effort was calculated by multiplying the number of camera traps by the number of effective sampling days (the total time between the first and last records in each sampling period, considering all sampling stations) [21].

Because the clade represents the main predictor of the activity in the genus Mazama (see Discussion for details), we classified the records into records obtained at night $(18: 00 \mathrm{~h}-05: 59 \mathrm{~h})$ and in the daytime period (06:00h-17:59h).

To describe the activity pattern, the independent records of Mazama spp. were grouped into 1-hour intervals for a total of 24 daily intervals. The overall data (grouping of all records), the data from each sampling period/design, and the data from each type of habitat sampled (internal roads - grouping Periods 1 and 4; and forest interior - grouping Periods 2 and 3) were considered. The Mardia-Watson-Wheeler test was used to assess whether there were differences in the daily distribution pattern of Mazama app. records. This test considers the time of each photographic record (independent inputs) and, based on the grouping of the data to be compared, draws random samples to determine whether the circular distribution of the data is identical to that of the original samples [22]. Initially, the 4 sample periods/designs were compared simultaneously (multisample) and then pairs of periods were compared with each other and with the overall pattern (pairwise). The same test was used to compare the types of habitat sampled (pairwise). The analyses were conducted using the program Oriana (version 4.0 ; [22]) and the level of significance was $5 \%$ (p-value $<0.05)$.

To represent the activity pattern graphically, rose diagrams and line graphs were used. To prepare the line graphs, 1-hour intervals and the percentage of records obtained in each interval were considered. Percentages were used so that any differences related to the absolute number of records did not affect the visual comparison of the activity patterns recorded. The activity peak was defined when the percentage of captures in any given hour was $50 \%$ greater than the hour with the greatest percent of captures [23].

\section{Results}

A total of 1,029 independent records of Mazama spp. were obtained during the study period, and the records were differently distributed among the sampling periods/designs. The Period 3 had the highest capture success, followed by Period 2 (Table 1). About $74.1 \%$ of all records were obtained in the daytime period, and the highest proportion of records in this period was also observed when considering each sampling period separately (69.6 to $90.9 \%$; Table 1 ). 
Table 1: Number of independent records $(\mathrm{N})$, with the proportion of nocturnal and diurnal records (\%; in parentheses), sampling effort (camerasday) and capture success (records/100 cameras-day) of brocket deer in the genus Mazama in the Reserva Natural Vale, southeastern Brazil, according to the sampling period (between Jun/2005 and Feb/2010).

\begin{tabular}{|c|c|c|c|}
\hline Sampling Period & N (Night / Day) & Sampling Effort & Capture Success \\
\hline Period 1 & $56(30.4 / 69.6)$ & 3,032 & 1.85 \\
\hline Period 2 & $378(23.8 / 76.2)$ & 3,468 & 10.90 \\
\hline Period 3 & $562(27.9 / 72.1)$ & 3,034 & 18.52 \\
\hline Period 4 & $33(9.1 / 90.9)$ & 1,033 & 3.20 \\
\hline Total & $1,029(25.9 / 74.1)$ & 10,567 & 9.74 \\
\hline
\end{tabular}

\section{Activity Pattern of Genus Mazama}

Records of Mazama spp. were obtained throughout the day (24 hours, with no periods of inactivity), and the genus was more active between 05:00h and 18:00h (Figure 2). There was a first peak in activity early in the morning, which extends until midafternoon, between 05:00h $\mathrm{h}$ and 15:00 $\mathrm{h}$, and a second peak late, at 17:00-18:00 h, in the evening (Table 2; Figure 2).

Table 2: Information on daily activity of brocket deer in the genus Mazama in the Reserva Natural Vale, southeastern Brazil, considering the general data and each sampling period (between Jun/2005 and Feb/2010).

\begin{tabular}{|c|c|c|c|c|c|}
\hline & General & Period 1 & Period 2 & Period 3 & Period 4 \\
\hline First activity peak & $0500-1500$ & $0900-1000$ & $0500-1800$ & $0600-1100$ & 0600 \\
\hline Second activity peak & $1700-1800$ & 1200 & - & $1700-1800$ & $0800-1100$ \\
\hline Third activity peak & - & $1400-1500$ & - & - & 1700 \\
\hline
\end{tabular}

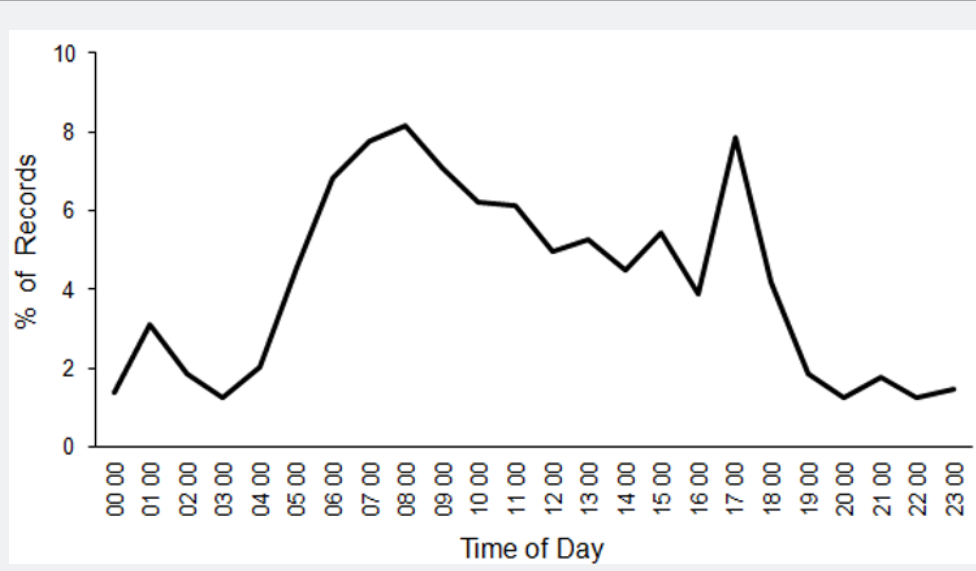

Figure 2: Hourly records of brocket deer in the genus Mazama in the Reserva Natural Vale, southeastern Brazil, considering the data obtained by camera trapping (between Jun/2005 and Feb/2010).

\section{Comparison of Activity Pattern Between Sampling Periods/Designs}

Table 3: Results of the Mardia-Watson-Wheeler test comparing the activity pattern of brocket deer in the genus Mazama in the Reserva Natural Vale, southeastern Brazil, considering the general data and each sampling period (between Jun/2005 and Feb/2010).

\begin{tabular}{|c|c|c|}
\hline Pairwise & W & P \\
\hline General x Period 1 & 0.356 & 0.837 \\
\hline General x Period 2 & 6.352 & 0.042 \\
\hline General x Period 3 & 4.383 & 0.031 \\
\hline General x Period 4 & 6.958 & 0.856 \\
\hline Period 1 x Period 2 & 0.310 & 0.403 \\
\hline Period 1 x Period 3 & 1.820 & 2 \\
\hline
\end{tabular}


JOJ Wildlife \& Biodiversity

\begin{tabular}{|c|c|c|}
\hline Period 1 x Period 4 & 4.340 & 0.114 \\
\hline Period 2 x Period 3 & 14.993 & $<0.001$ \\
\hline Period 2 x Period 4 & 8.358 & 0.015 \\
\hline Period 3 x Period 4 & 7.279 & 0.026 \\
\hline
\end{tabular}

Considering the overall pattern and each sampling period/ design separately, the activity pattern of Mazama spp. varied in relation to the hours with the highest activity and/or the number of activity peaks during the day (Table 2). The daily distribution pattern of Mazama spp. records differed significantly between the sampling periods/designs $(\mathrm{W}=22.957, \mathrm{P}<0.001)$. The pairwise comparisons revealed significant differences between overall $\times$ Period 2, overall $\times$ Period 4, Period $2 \times$ Period 3, Period $2 \times$ Period 4, and Period $3 \times$ Period 4 (Table 3; Figure 3)
$\mathbf{A}$

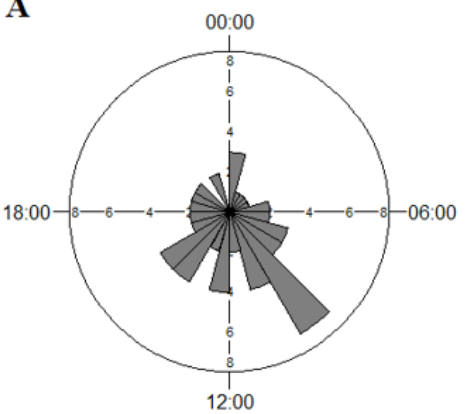

C

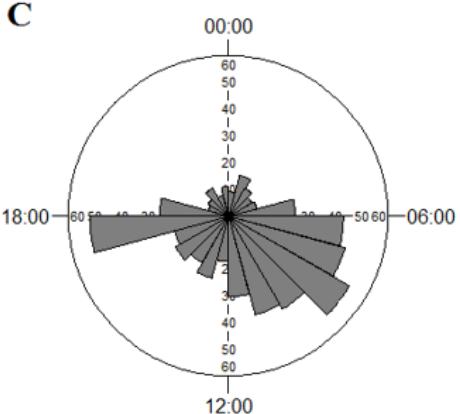

B

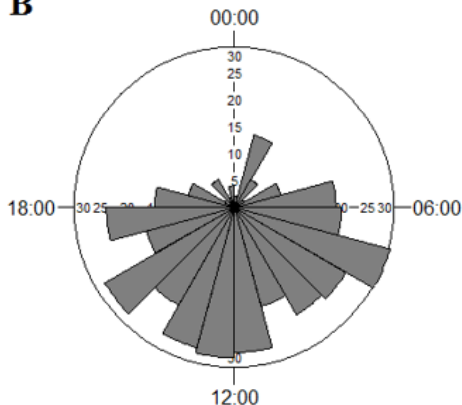

D

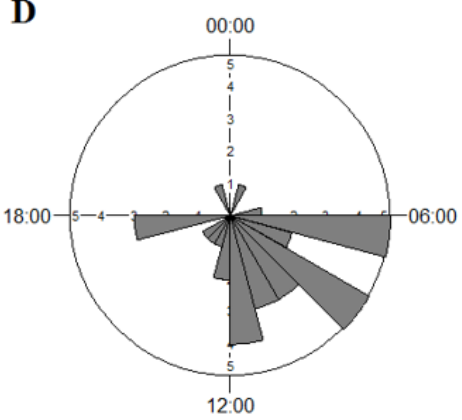

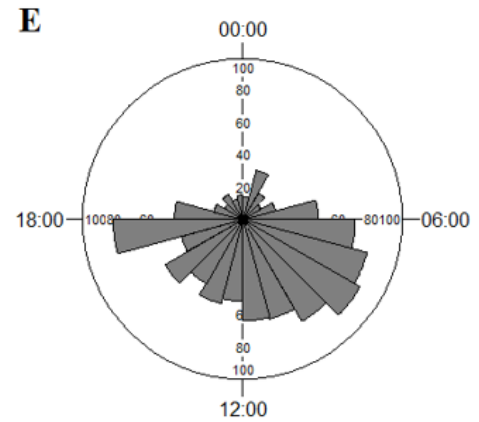

Figure 3: Activity pattern of brocket deer in the genus Mazama in the Reserva Natural Vale, southeastern Brazil, considering the data obtained by camera trapping in each sampling period (Period $1=A$, Period $2=B$, Period $3=C$, and Period $4=D$ ) and the overall data $(E)$.

\section{Unpaved Road X Forest Interior Comparison}

When the sampled habitats were analyzed separately, the proportion of records associated with the first and second activity peaks differed, with the first peak being more expressive for unpaved roads, and the second peak for forest interior (Figures 4 and 5). However, the daily distribution pattern of Mazama spp. records was similar between internal unpaved roads and the forest interior $(\mathrm{W}=3.011 ; \mathrm{P}=0.222)$. 


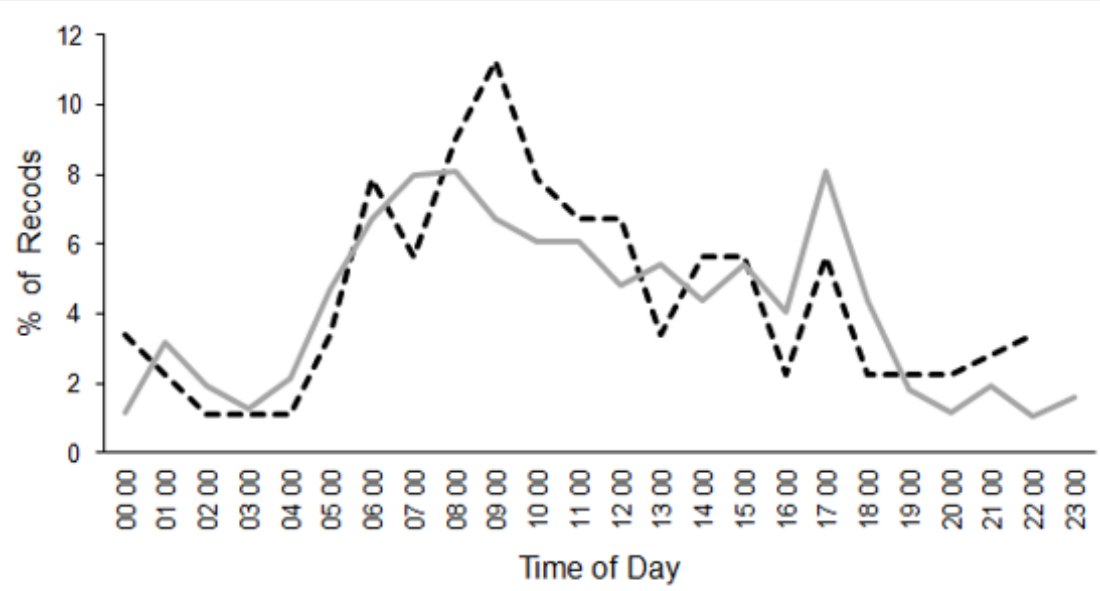

-- Unpaved roads _- Forest interior

Figure 4: Hourly records of brocket deer in the genus Mazama in the Reserva Natural Vale, southeastern Brazil, considering the data obtained in each habitat sampled (internal unpaved roads and the forest interior).

A

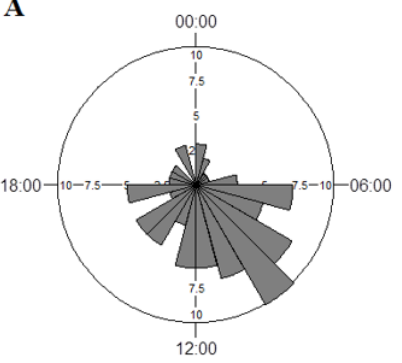

B

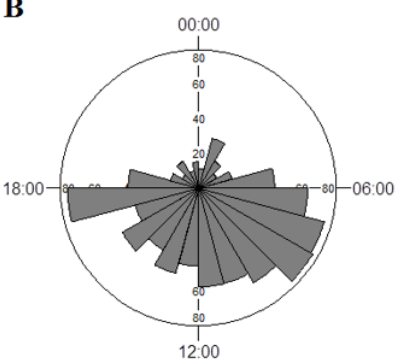

Figure 5: Activity pattern of brocket deer in the genus Mazama in the Reserva Natural Vale, southeastern Brazil, considering the data obtained by camera trapping in each habitat sampled (internal unpaved roads $=\mathrm{A}$, and forest interior $=\mathrm{B}$ ).

\section{Discussion}

The genus Mazama was active over the entire 24 hours, with more intense activity during the day, comprising a crepusculardiurnal pattern in the RNV. Mazama activity over 24 hours, considering either a single species or the combined records of 2 sympatric species (one from the red clade and another from the gray clade) has also been observed in Ecuador [4], Peru [16], Bolivia [13,15], Argentina [11], and Brazil (Amazon, Pantanal, and Atlantic Forest; [14]), but these results differ from those of Ferreguetti et al. [12] based on data also collected in the RNV.

From the comparison of the results of previous studies performed with M. americana and M. gouazoubira, we observe that there are peculiarities in the activity time for the same species of brocket deer between sites (intraspecific variations), and the differences are related to the hours of more intense activity and occasional periods of inactivity. These variations may be attributed to differences in the photoperiod between the sampled sites, which varies with latitude [5]; local effect of altitude associated with topography on the incidence of solar rays inside the vegetation at each study area [23]; differences in the ambient temperature between regions [6, 23]; local variations in the response to competition between Mazama spp. [15]; the size of the studied remnants [6]; or changes in the activity pattern in response to the presence of hunters [6]. Blake et al. [4] obtained records of M. americana during the day and night and found an activity peak in the early morning and another in the late afternoon. Di Bitetti et al. [11] and Gómez [13] observed a similar pattern, although the first activity peak occurred at the end of the night, and the species was less active during the hottest hours of the day. Rivero et al. [15] recorded more intense activity between sunset and sunrise and no records in the early afternoon. Tobler et al. [16] obtained more records in the late afternoon and throughout the night, with no records in the hottest hours of the day. In Brazil, Oliveira et al. [14] recorded more intense activity of M. americana at night, especially before sunrise, in the Amazon, and attained a greater number of records after sunset and during the night, in the Atlantic Forest. Ferreguetti et al. [12], also in Atlantic Forest, obtained records of $M$. americana only at night, with more intense activity after midnight. For M. gouazoubira, Blake et al. [4] found greater activity during the day until sunset and inactivity at night. Rivero 
et al. [15] and Tobler et al. [16] obtained records over $24 \mathrm{~h}$, with more intense activity in the early morning [15] or throughout the diurnal period [16]. In the Brazilian Pantanal, Oliveira et al. [14] recorded more intense activity of $M$. gouazoubira early in the morning and late at afternoon. In the Atlantic Forest, Ferreguetti et al. [12] recorded the species only during the day, with activity peak early in the morning and in the hottest hours of the day.

Ferreguetti et al. [12] classified M. americana as nocturnal and M. gouazoubira as diurnal, with temporal segregation between the 2 species, and 2 periods during the day with no records of the genus (from $04: 00 \mathrm{~h}$ to $06: 00 \mathrm{~h}$, and $17: 00 \mathrm{~h}$ to 20:00h). Although the species were not differentiated in the present study, the gaps in records noted by Ferreguetti et al. [12] were not observed, highlighting that some of the activity peaks recorded here overlap the times without records in the previous study. In addition, according to few records identified by cervid specialists (see Materials and Methods for details), we recorded M. americana at $17: 21 \mathrm{~h}, 18: 20 \mathrm{~h}, 18: 52 \mathrm{~h}, 22: 31 \mathrm{~h}, 00: 05 \mathrm{~h}$ and $02: 10 \mathrm{~h}$ (some of which correspond to the second gap identified by Ferreguetti et al. [12]) while M. gouazoubira was recorded by us at $08: 08 \mathrm{~h}, 08: 29 \mathrm{~h}, 09: 36 \mathrm{~h}$ and $14: 52 \mathrm{~h}$ in the RNV. The gaps recorded by Ferreguetti et al. [12] also contrast with the observed in other locations for the genus Mazama [4, 11,13-16]. The differences in the activity pattern of M. americana and $M$. gouazoubira (interspecific variations) seem to be related to an effect of phylogeny, and the clade represents the main predictor of the activity of the species, with the red clade being more nocturnal and the gray clade more diurnal [14]. If this pattern is also observed in the RNV, it is probable that our dataset gathers a larger number of records of M. gouazoubira, the local representative of the gray clade. This observation applies to overall data, to the data from each sampling period/design and, consequently, to each habitat sampled. Ferreguetti et al. [12] also obtained a greater number of records of M. gouazoubira by camera traps and transect surveys, suggesting that this species may be more abundant in RNV than M. americana.

Although there was no difference in the activity pattern between the sampled habitats in the present study, there was difference between Periods 2 and 3, which included the forest interior dataset. By contrast, the periods in which sampling was conducted along unpaved roads did not differ from each other. It is worth noting that there was also a difference between the pattern detected when the camera traps were only installed in the north subarea (Period 4) and when the designs included sampling throughout the entire RNV (Periods 2 and 3). These variations in activity pattern should not be related to differences in the proportion of records of the species/clades sampled, suggesting that it is related to different behavioral responses of Mazama spp. to spatial variations in habitat on a local/regional scale. In this respect, the Mazama camera trapping data may have been influenced by small differences within the same type of habitat (such as the distance to the nearest internal road) and/or regional peculiarities within the same remnant (such as among the RNV subareas) highlighting that sampling was always conducted in dense lowland forest. However, the sum of the records from Periods 2 and 3 (forest interior) diluted the local effect, resulting in a pattern like the data from Periods 1 and 4 combined (internal roads). Similarly, sampling along roads throughout the entire RNV (Period 1) reduced the regional effect (Period 4) so that the data were like those from the off-road samplings (Periods 2 and 3 ).

The results of the present study corroborate those of SrbekAraujo \& Chiarello [7], who indicated that sampling design affects the collection of mammal records using camera traps, reinforcing that the risk of sample bias should be weighed during study design. According to the data presented here, the sampling design may also result in different activity patterns for the same species/taxa, which may be related to behavioral differences in response to spatial variations in habitat on a local/regional scale. Once the detection rate by camera traps is determined by the level of activity of the species in a specific environment or habitat, the capture rate will be proportional to their level of activity in each place [7] and at each time of day [24]. For this reason, the integration of sample designs becomes more representative for the characterization of the general activity pattern of the species, encompassing the variation in the use of landscape components (intensity of use) and the peculiarities in the pattern of use (time of day, for example) of each element of the landscape. Indeed, the integration of sampling periods diluted the differences between sampling designs used here, highlighting that the types of habitat sampled in the present study did not significantly affect the recorded activity pattern of Mazama spp., which was similar between the internal unpaved roads and the forest interior.

Regardless of the sampling design used, none of the activity patterns observed for the genus Mazama in the present study was like the pattern reported by Ferreguetti et al. [12] for the same study area (considering the 2 species as a unit). It may be due to differences in sampling design (location of camera traps, for example), eventual inaccuracy in species identification, and/or the randomization procedure proposed by Ferreguetti et al. [12] to "correct" records that could not be identified (uncertain identification). According to the authors, when the identification was uncertain, they "randomized the unidentified records using the proportion of each species found in the total number of transect sightings and camera trap records" and "the 2 species were recorded in similar proportions in the 2 sampling procedures" [12]. This randomization procedure is based on the identified records, so it is sensitive to accuracy in species identification, which can generate biased results. In addition, unidentified records are not necessarily distributed between species in the same proportion as identified records (or between transect sightings and camera trap records), which may be influenced by the greater ease of identification of one species over another, considering the quality of the photographic 


\section{JOJ Wildlife \& Biodiversity}

records (e.g. light conditions, positioning/angle of the animal, and proximity to the equipment), highlighting that the studied species are very similar physically, with subtle diagnostic morphological characters.

\section{Conclusion}

Our results confirm that the genus Mazama is active throughout 24-hour period, with no periods of inactivity, also in southeastern Brazil, similarly, to results from other regions in South America. Furthermore, we recommend the use of different sampling designs to better determine the activity pattern of the focal species in camera trap studies because details of the data collection strategies can influence the data obtained and thus affect the recorded patterns.
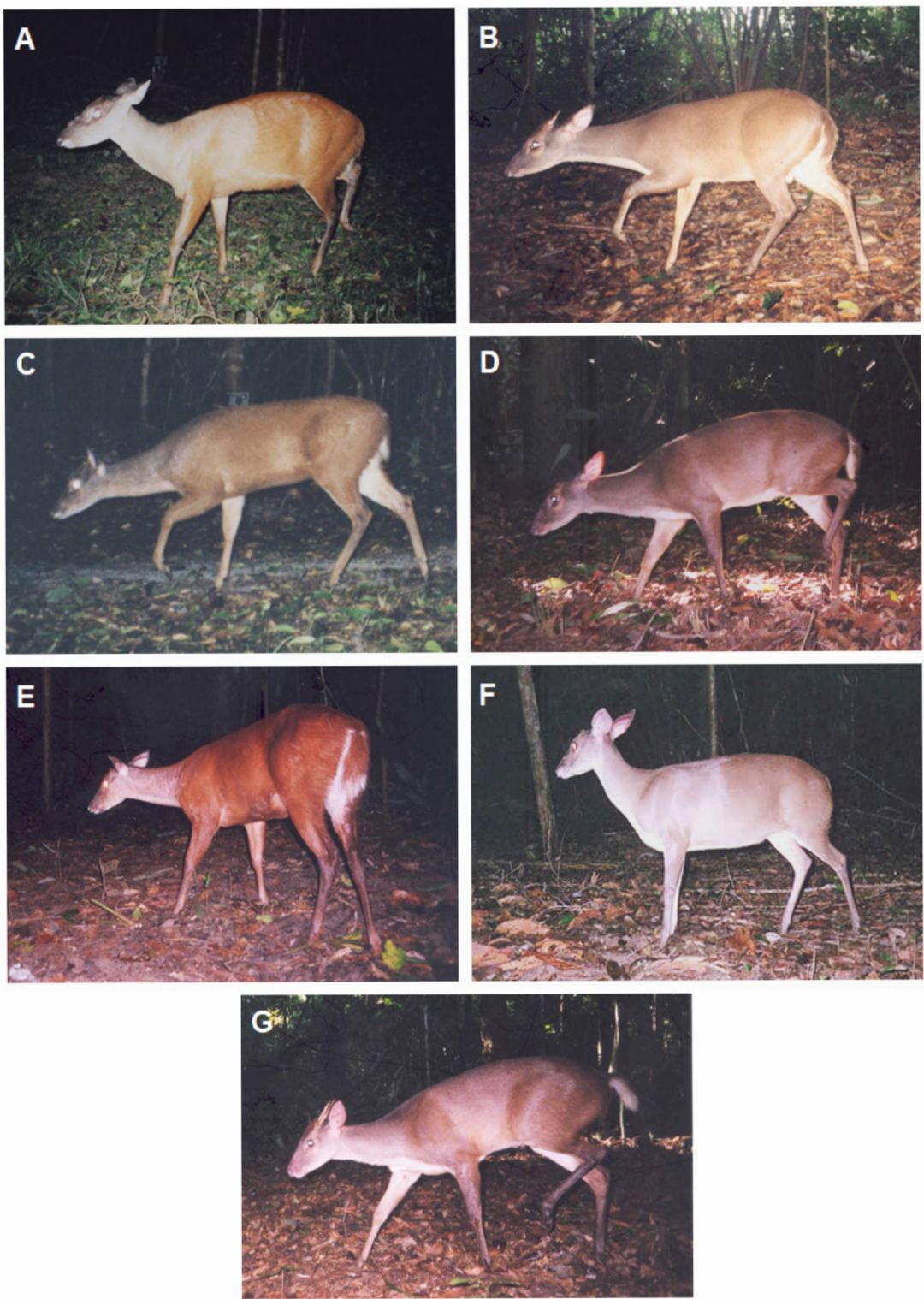

Appendix 1: Brocket deer in the genus Mazama recorded in the Reserva Natural Vale, southeastern Brazil: M. americana (A), M. gouazoubira (B), red clade (C and E), gray clade (D and F) and potential hybrid (G). 


\section{References}

1. Kronfeld Schor N, T Dayan (2003) Partittioning of time as an ecological resource. Annual Review of Ecology, Evolution, and Systematics 34: 153-181.

2. Challet E, P Pévet (2003) Interactions between photic and nonphotic stimuli to synchronize the máster circadian clock in mammals. Frontiers in Bioscience 8: s246-257.

3. Davidson A J, M Menaker (2003) Birds for a feather clock together-sometimes: social synchronization of circadian rhythms. Curr Opin Neurobio 13(6): 765-769.

4. Blake J G , D Mosquera B A, Loiselle, K Swing, J Guerra, D Romo (2012) Temporal activity patterns of terrestrial mammals in lowland rainforest of Eastern Ecuador. Ecotropica 18: 137-146.

5. Dias L C S , C S São Bernardo, A C Srbek-Araujo (2016) Daily and seasonal activity patterns of the solitary tinamou (Tinamus solitarius) in the Atlantic Forest of southeastern Brazil. Wilson Journal of Ornithology 128(4): 885-894.

6. Norris D , F Michalski, C A Peres (2010) Habitat patch size modulates terrestrial mammal activity patterns in Amazonian forest fragments. Journal of Mammalogy 91(3): 551-560.

7. Srbek-Araujo A C, A G Chiarello (2013) Influence of camera-trap sampling design on mammal species capture rates and community structures in southeastern Brazil. Biota Neotropica 13(2): 51-62.

8. Duarte J M B , S González, J E Maldonado (2008) The surprising evolutionary history of South American deer. Molecular Phylogenetics and Evolution 49(1): 17-22.

9. Tiepolo L M, W M Tomas (2006) Ordem Artiodactyla [Order Artiodac tyla] pp 283-300 In: N R Reis, A L Peracchi, W A Pedro, I P Lima (eds) Mamíferos do Brasil [Mammlas of Brazil]. Edifurb, Londrina, Brazil.

10. Paglia A P , G A B Fonseca, A B Rylands, G Herrmann, L M S Aguiar, et al. (2012) Lista Anotada dos Mamíferos do Brasil / Annotated Checklist of Brazilian Mammals. Occasional Papers in Conservation Biology 6: 1-76.

11. Di Bitetti M S , Paviolo A , C A Ferrari, C De Angelo, Y Di Blanco (2008) Differential responses to hunting in two sympatric species of brocket deer (Mazama americana and M. nana. Biotropica 40(5): 636-645.

12. Ferreguetti Á C , W M Tomás, H G Bergallo (2015) Density, occupancy, and activity pattern of two sympatric deer (Mazama) in the Atlantic Forest, Brazil. Journal of Mammalogy 96(6): 1245-1254.
13. Gómez H , R B Wallace, G Ayala, R Tejada (2005) Dry season activity periods of some Amazonian mammals Studies on Neotropical. Fauna and Environment 40(2): 91-95.

14. Oliveira M L , P H F Peres, A Vogliotti, F Grotta Neto, A D K Azevedo, et al. (2016) Phylogenetic signal in the circadian rhythm of morphologically convergent species of Neotropical deer. Mammalian Biology 81(3): 281-289.

15. Rivero K G , B Rumiz, A B Taber (2005) Differential habitat use by two sympatric brocket deer species (Mazama americana and M.gouazoubi$\mathrm{ra}$ ) in a seasonal Chiquitano Forest of Bolivia. Mammalia 69(2): 169183.

16. Tobler M W , S Carrilo-Percastegui, G Powell (2009) Habitat use, activity patterns and use of mineral licks by five species of ungulate in southeastern Peru. Journal of Tropical Ecology 25: 261-270.

17. FSOSMA \& INPE (2019) Atlas dos remanescentes florestais da Mata Atlântica: Período 2017-2018 [Atlas of the Atlantic Forest Remnants Period 2017-2018]. Fundação SOS Mata Atlântica \& Instituto Nacional de Pesquisas Espaciais, São Paulo, Brazil.

18. Jesus R M, S G Rolim (2005) Fitossociologia da Mata Atlântica de Tabuleiro [Phytosociology of the Lowland Atlantic Forest]. Boletim SIF 19: 1-149.

19. Alvares C A , J L Stape, P C Sentelhas, P C Gonçalves, G Sparovek (2014) Koppën's climate classification map for Brazil. Meteorologische Zeitschrift 22(6): 711-728.

20. Kierulff M C M , L H S Avelar, M E S Ferreira, K F Povoa, R S Bérnils (2014) Reserva Natural Vale: história e aspectos físicos [Vale Natural Reserve: history and physical aspects]. Ciência \& Ambiente 49: 7-40.

21. Srbek-Araujo A C,A G Chiarello (2005) Is camera-trapping an efficient method for surveying mammals in Neotropical forests? A case study in south-eastern Brazil. Journal of Tropical Ecology 21: 121-125.

22. Kovach Computing Services (2009) Oriana Users' Manual Kovach Computing Services. Pentraeth, Wales, United Kingdon.

23. Magalhães L M, A C Srbek-Araujo (2019) Plasticity in the timing of activity in the Red-rumped Agouti, Dasyprocta leporina (Mammalia: Rodentia), in the Atlantic Forest of southeastern Brazil. Biota Neotropica 19: e20180625.

24. Rowcliffe J M, R Kays, B Kranstauber, C Carbone, P A Jansen (2014) Quantifying levels of animal activity using camera trap data. Methods in Ecology and Evolution 5: 1170-1179.

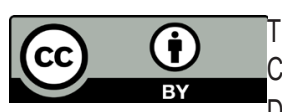

This work is licensed under Creative Commons Attribution 4.0 License

DOI: 10.19080/JOJWB.2019.01.555560

\section{Your next submission with Juniper Publishers will reach you the below assets}

- Quality Editorial service

- Swift Peer Review

- Reprints availability

- E-prints Service

- Manuscript Podcast for convenient understanding

- Global attainment for your research

- Manuscript accessibility in different formats

( Pdf, E-pub, Full Text, Audio)

- Unceasing customer service

Track the below URL for one-step submission

https://juniperpublishers.com/online-submission.php 